\title{
Personalien und Tagesnachrichten
}

Prof. Dr. P. Lins $\beta r$ in Tubingen wurde zum Ehrenmitglied der griechi-schen und türkischen Gesellschaft für Dermatologie, Prof. P. Miihlens in Hamburg zum korrespondierenden Mitglied der medizinischen Akademie in Caracas gewählt.

Prof. P. Mulzer in Hamburg wurde von der argentinischen Cresellschaft für Haut- und Geschlechtskrankheiten zum korrespondierenden Mitglied er-nannt.

In Budapest fand vom 13. bis 21. September 1935 der 9. Internationale Dermatologenkongreß unter recht großer Beteiligung statt. Dem aus Budapest gebürtigen, fast 80 Jahre alten Dr. Jean Darier, der durch sein ausgezeich-netes Lehrbuch ein Praeceptor mundi geworden ist, wurde durch Ernennung zum Ehrendoktor eine besondere Huldigung bereitet; auch Sabouraud, der die erste Ehrenansprache hielt, wurde sehr gefeiert. Das Programm war ein sehr reichhaltiges, so daß auch Parallelsitzungen vielfach stattfinden mußten. Die Sorgfalt aller Vorbereitungen, die eindrucksvolle Begrüßung und die große un-gemein liebenswürdige Gastlichkeit alien Gästen gegenüber $\Lambda$ vurden dankbar anerkannt. Vor Beginn der sehr feierlich eröffneten Tagung traten zahlreiche Sonderausschüsse zusammen, die viele Fragen unseres Faches zu klären und weiterzuführen bestimmt sind. Wie wir hören, soil für den nächsten Kongreß Madrid als Tagungsort ausersehen sein.

In Form einer Gemeinschaftsarbeit in Staat und Stadt ist ein allgemeines Institut gegen die Geschwulstkrankheiten in Berlin am Rudolf-Virchow-Krankenhaus errichtet worden, das der Behandlung, Forschung und Lehre dienen soil. Seine Einrichtung wird in enger Fühlung mit dem Reichsausschuß für Krebsbekämpfung unter Prof. Borst durchgeführt. Als Kurator $\Lambda$ virkt Prof.

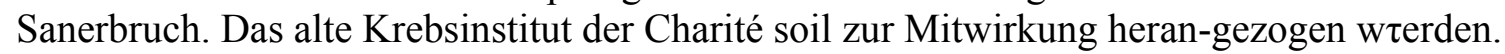
Die „British Association of Dermatology and Syphílology” hielt ihre 15. Jahrestagung in Sheffield am 5. und 6. Juli 1935. Hall sprach über Der-matologisches von gestern und heute, Schaumann, Stockholm, über Lympho-granulomatosis benigna, Brain über biologische Therapie bei Vergiftungen, Smith über Immunität bei chr. Furunkulose, Forman über Erythema nodosum und Kinnear über Streptokokkendermatitis; eine Diskussion über Ekzem wurde von Adamson und Ingram eingeleitet. Ferner wurden etwa 20 Fälle vor-gestellt. 